\title{
BLOCK PUNCH INDEX (BPI) DAN POINT LOAD INDEX (PLI) UNTUK MEMPREDIKSI NILAI KUAT TEKAN BATUAN PENYUSUN LERENG TAMBANG GUNA MENCEGAH TERJADINYA LONGSORAN DI CV. BARA MITRA KENCANA, SAWAHLUNTO
}

\author{
Refky Adi Nata ${ }^{1}$, Alfi Sabri ${ }^{2)}$ \\ Program Studi Pertambangan Sekolah Tinggi Teknologi Industri (STTIND) Padang \\ Email.refkyadi@yahoo.co.id
}

\begin{abstract}
Abstrak: Lereng di lokasi penambangan CV. Bara Mitra Kencana memiliki kondisi batuan yang tergolong lunak (soft). Batuan sedimen yang menjadi batuan penyusun lereng berupa batu pasir, batu bara dan batu lanau jika terkena oleh air yang jenuh berakibat akan mengurangi daya dukungnya. Perusahaan memiliki kendala dalam menentukan nilai faktor keamanan dari lereng yang terbentuk baik secara alami maupun buatan akibat proses penambangan. Penelitian ini bertujuan untuk menentukan nilai kuat tekan batuan penyusun lereng dan menentukan parameter bobot isi batuan, serta nilai faktor keamanan lereng di lokasi penambangan CV. Bara Mitra Kencana guna sebagai acuan dalam menganalisis kstabilan dari lereng tambang. Proses tahapan penelitian dilakukan dengan pengambilan sampel batuan yang menyusun lereng tambang CV. Bara Mitra Kencana, Sawahlunto. Penelitian ini menghasilkan nilai UCS rata-rata dari BPI untuk batupasir sebesar $0.8111 \mathrm{MPa}$ dan nilai UCS rata-rata untuk batulanau sebesar $1.2675 \mathrm{MPa}$, persamaan linear yang dihasilkan antara BPI dan UCS untuk batupasir, yaitu $\mathrm{y}=5.099 \mathrm{x}$ dengan regresi $\left(\mathrm{R}^{2}=1\right)$ dan untuk persamaan linear yang dihasilkan antara BPI dan UCS untuk batulanau, yaitu $\mathrm{y}=5.1 \mathrm{x}$ dengan regresi $\left(R^{2}=1\right)$. Sedangkan untuk pengujian PLI untuk kedua sampel berupa batulanau dan batupasir diketahui bahwasannya nilai UCS rata-rata untuk batupasir sebesar $0.8463 \mathrm{MPa}$ dan nilai UCS rata-rata untuk batulanau sebesar $0.7386 \mathrm{MPa}$ persamaan linear yang dihasilkan antara PLI dan UCS untuk batupasir yaitu y $=15.31 \mathrm{x}$ dengan regresi $\left(\mathrm{R}^{2}=\right.$ 1) dan untuk persamaan linear yang dihasilkan antara PLI dan UCS untuk batulanau, yaitu y $=15.31 \mathrm{x}$ dengan regresi $\left(\mathrm{R}^{2}=1\right)$. Hasil analisa kestabilan lereng menggunakan metode grafik Hoek dan Bray (1981) diperoleh bahwasannya nilai FK untuk lereng BMK 35 kisaran $2.62-2.67$ dan lereng dengan FK > 1 dinyatakan aman.
\end{abstract}

Kata kunci: Kuat Tekan, Faktor Keamanan Lereng, batuan.

\section{PENDAHULUAN}

Tujuan uji tekan UCS adalah untuk mengukur kuat tekan uniaksial dari sebuah contoh batuan dalam geometri yang beraturan, baik dalam bentuk silinder, balok maupun prisma dalam satu arah (uniaksial). Tujuan utama uji ini adalah untuk klasifikasi kekuatan dan karakterisasi batuan utuh. Hasil uji ini menghasilkan beberapa informasi yaitu; kurva tegangan regangan, kuat tekan uniaksial, Modulus Young, Nisbah Poisson, fraktur energi dan spesifik fraktur energi [1].

Pengujian ini dilakukan menggunakan mesin tekan (compression mechine) dan dalam pembebanannya mengikuti standar dari International Society for Rock Mechanics (ISRM, 1981) [1]. Secara teoritis penyebaran tegangan di dalam contoh batuan searah dengan gaya yang dikenakan pada contoh tersebut. Akan tetapi, pada kenyataannya arah tegangan tidak searah dengan gaya yang 
dikenakan pada contoh. Hal ini terjadi karena ada pengaruh dari plat penekan pada mesin tekan yang berbentuk bidang pecah yang searah dengan gaya, berbentuk cone [2].

Uji point load Index merupakan uji indeks yang telah secara luas digunakan untuk memprediksi nilai UCS suatu batuan secara tidak langsung di lapangan. Hal ini disebabkan prosedur pengujian yang sederhana, preparasi conto yang mudah dan dapat dilakukan langsung di lapangan. Peralatan yang digunakan mudah dibawabawa, tidak begitu besar dan cukup ringan sehingga dapat dengan cepat diketahui kekuatan batuan di lapangan, sebelum dilakukan pengujian di laboratorium [1].

Pada awalnya pengujian punch dilakukan oleh Lacharite yang menggunakan uji shear punch untuk mengetahui nilai kuat geser dari batupasir. Dia mengatakan bahwa ketika ukuran diameter sampel bertambah maka nilai kuat gesernya juga akan bertambah dan ketika ketebalan sampel yang divariasikan tidak terjadi perubahan yang signifikan pada nilai kuat gesernya [6].

Kemudian pengujian punch dikembangkan menjadi alat block punch index (BPI) di Belanda yang dilakukan oleh Taselaar (1982) yang mana alat ini digunakan untuk menetukan kuat geser batuan. Bentuk asli dari alat block punch index (BPI) pertama kali dikembangkan di Laboratorium Teknik Geologi di Universitas Teknologi Delft [6].

Pada tahun 1988, Schrier menggunakan alat uji block punch index (BPI) yang dirancang oleh Taselaar untuk menguji sampel sebanyak 1185 sampel berbentuk silinder, yang memiliki ketebalan $10 \mathrm{~mm}$ dan diameter $40 \mathrm{~mm}$. Ada 9 jenis batuan yang dijadikan sampel pada penelitian ini, yaitu breksi, kalkarenit, calcilutite, dunit, gneiss, batukapur, marmer, batu lumpur dan batupasir. Pengujian ini dilakukan unutk mengetahui hubungan antara UCS, kuat tarik Brazilian dan block punch index (BPI). Schrier menyarankan bahwa uji block punch index
(BPI) adalah pengujian indeks yang praktis untuk memperkirakan nilai kuat tekan UCS [3].

$\begin{array}{ccc}\text { Pengujian } & \text { UCS } & \text { (Unconfined } \\ \text { Compressive } & \text { Strength) } & \text { merupakan }\end{array}$
pengujian kuat tekan dalam satu arah dengan sampel geometri batuan yang beraturan, baik berbentuk silinder, balok dan prisma. Pada tambang bawah tanah pengukuran kuat tekan menjadi parameter yang penting dalam kestabilan pillar. Uji ini menggunakan mesin tekan (compression machine) dan dalam pembebanannya mengikuti standard International Society Rock Mechanics (ISRM) [5].

Pengujian point load merupakan pengujian yang telah dikenal untuk memprediksi nilai UCS suatu batuan secara tidak langsung di lapangan. Hal ini disebabkan prosedur pengujiannya sederhana, preparasi sampel mudah dan dapat dilakukan dilapangan [8]. Rock Quality Designation disingkat dengan RQD dikenalkan oleh Deere tahun 1967. RQD ini berguna untuk mengetahui kualitas massa batuan dari core hasil pemboran. RQD ini mendefinisikan persentase core yang utuh per $100 \mathrm{~mm} \mathrm{(4}$ inches) dari total panjang core [4].

Spasi rekahan adalah jarak tegak lurus antara bidang-bidang rekahan yang memiliki kesamaan arah dan biasanya diamati dilapangan dengan bantuan meteran. Sedangkan kondisi rekahan terdiri atas kekasaran, lebar bukaan, panjangnya (presistensi) dan pelapukan pada rekahan [9].

Stand Up Time merupakan waktu yang diperlukan batuan untuk menyangga dirinya sendiri sebelum terjadi keruntuhan. Hasil pembobotan nilai RMR nantinya akan di plot kedalam kurva sehingga kita dapat mengetahui stand up time dari massa batuan. Nilai RMR yang diplotkan ialah nilai RMR total yang didapat dari penjumlahan 5 parameter RMR seperti: bobot UCS, bobot RQD, bobot untuk jarak 
kekar, bobot kondisi kekar dan bobot kondisi air tanah [7].

\section{METODE PENELITIAN}

\section{Jenis Penelitian}

Jenis penelitian tergolong kedalam applied research. Penlitian applied research merupakan penelitian yang menerapkan kajian, menguji kajian, mengevaluasi kemampuan dari suatu teori kajian, dan memecahkan permasalahan permasalahan yang ada.

\section{Tahapan Penelitian}

Langkah - langkah dalam pengambilan data yaitu:

1. Pengambilan Sampel batuan dilakukan di 5 (lima) stasiun pengamatan dan diuji kuat tekannya dengan alat yang dirancang oleh peneliti.

2. Pengukuran dimensi lereng yang akan dianalisa faktor keamananan (FK) nya.

3. Pengujian sifat fisik batuan seperti (bobot isi asli, bobot isi kering dan bobot isi jenuh).

Beberapa data yang diambil langsung dari pengukuran dan pengamatan di lapangan seperti sampel batuan, dimensi lereng (ketinggian, lebar berm, dan kemiringan) dan pengujian bobot isi batuan (bobot isi asli, bobot isi kering dan bobot isi jenuh) di lereng CV. Bara Mitra Kencana. Selain itu data yang dibutuhkan antara lain dari literatur, buku referensi dan laporan perusahaan, seperti laporanlaporan CV. Bara Mitra Kencana berupa: peta situasi penambangan, statigrafi, geologi daerah, topografi dan kajian geoteknik di CV. Bara Mitra Kencana.

Pengolahan data kuat tekan pada penelitian ini menggunakan program Microsoft excel untuk memperoleh persamaan empiris. Pengolahan data faktor keamanan (fk) lereng dengan menggunakan kurva hook and bray. Tahapan-tahapan dari penelitian yang dilakukan dapat dilihat melalui Gambar 1 diagram alir penelitian.

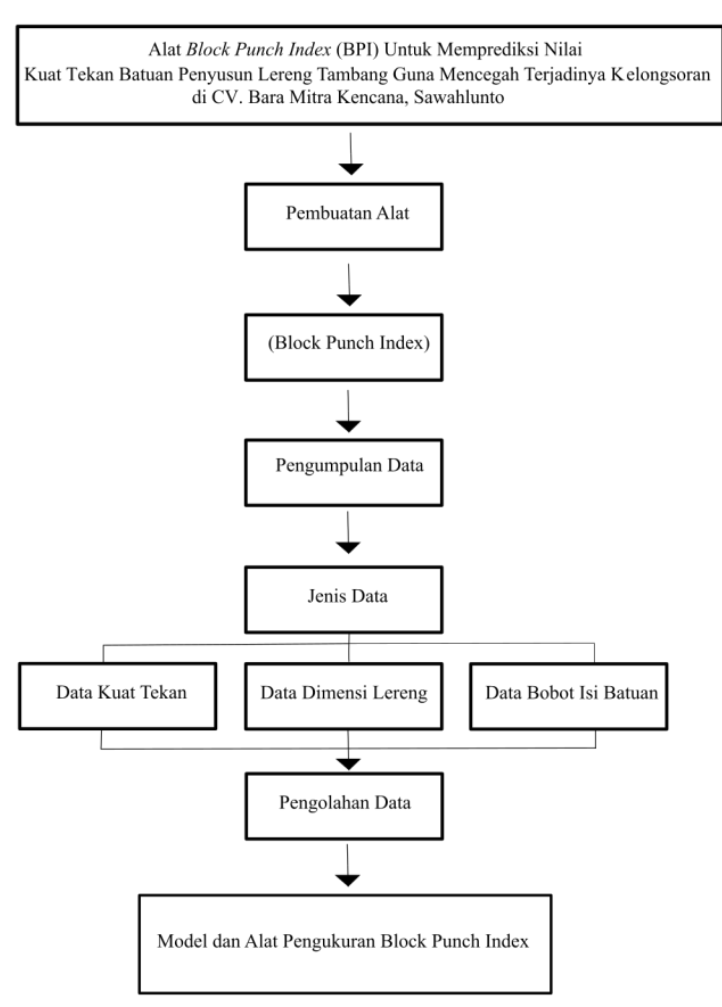

Gambar 1. Diagram Alir Penelitian

\section{HASIL DAN PEMBAHASAN}

\section{Prediksi Nilai UCS Menggunakan Nilai BPI}

Sampel yang digunakan adalah sampel batuan penyusun lereng seperti terlihat pada Gambar 2.

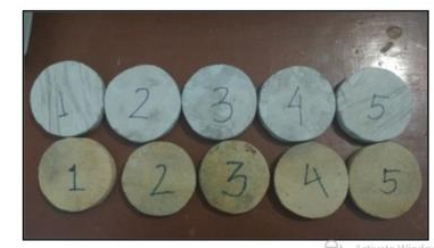

Gambar 2. Hasil Preparasi Sampel Batuan untuk Uji BPI

Nilai BPI yang dihitung dan prediksi nilai UCS masing-masing batuan. tertera pada tabel 1 .

\section{Tabel 1}




\section{Prediksi Nilai UCS dari Perhitungan Nilai BPI}

\begin{tabular}{|c|c|c|c|c|c|c|c|}
\hline $\begin{array}{c}\text { Kode } \\
\text { Sampel }\end{array}$ & $\mathrm{r}(\mathrm{cm})$ & $\begin{array}{c}\mathrm{t} \\
(\mathrm{cm})\end{array}$ & $\mathrm{K}(\mathrm{cm})$ & $\begin{array}{c}\mathrm{F} \\
\left(\mathrm{kg} / \mathrm{cm}^{2}\right)\end{array}$ & $\begin{array}{c}\text { BPI } \\
\text { (MPa) }\end{array}$ & $\begin{array}{c}\text { UCS } \\
\text { (MPa) }\end{array}$ & $\begin{array}{l}\text { UCS rata- } \\
\text { rata (MPa) } \\
\end{array}$ \\
\hline BP1 & 2.51 & 1.01 & 1.5 & 18 & 0.1822 & 0.9292 & \multirow{5}{*}{0.8111} \\
\hline $\mathrm{BP} 2$ & 2.525 & 1.002 & 1.5 & 15 & 0.1520 & 0.7752 & \\
\hline BP3 & 2.551 & 1.002 & 1.5 & 13 & 0.1303 & 0.6645 & \\
\hline BP4 & 2.56 & 1.001 & 1.5 & 20 & 0.1999 & 1.0194 & \\
\hline BP5 & 2.54 & 1.003 & 1.5 & 13 & 0.1308 & 0.6672 & \\
\hline BL1 & 2.52 & 1.002 & 1.5 & 30 & 0.3049 & 1.5549 & \multirow{5}{*}{1.2675} \\
\hline BL2 & 2.53 & 1.03 & 1.5 & 28 & 0.2756 & 1.4054 & \\
\hline BL3 & 2.5175 & 1.045 & 1.5 & 25 & 0.2438 & 1.2435 & \\
\hline BL4 & 2.553 & 1.102 & 1.5 & 23 & 0.2095 & 1.0686 & \\
\hline BL5 & 2.5125 & 1.125 & 1.5 & 23 & 0.2088 & 1.0651 & \\
\hline
\end{tabular}

Dari pengujian BPI untuk kedua sampel berupa batulanau dan batupasir diketahui bahwasannya nilai UCS rata-rata untuk batupasir sebesar $0.8111 \mathrm{MPa}$ dan nilai UCS rata-rata untuk batulanau sebesar 1.2675 MPa. Persamaan empiris yang dihasilkan antara BPI dan UCS untuk batupasir, yaitu y $=5.099 \mathrm{x}$ dengan regresi $\left(\mathrm{R}^{2}=1\right)$ dan BPI terhadap UCS untuk batulanau, yaitu $\mathrm{y}=5.1 \mathrm{x}$ dengan regresi $\left(\mathrm{R}^{2}=1\right)$.

\section{Prediksi Nilai UCS Menggunakan Nilai PLI}

Sampel yang digunakan dalam pengujian PLI dapat dilihat pada Gambar 3.

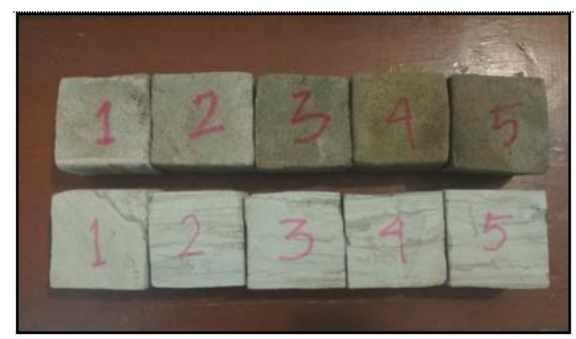

Gambar 3. Hasil Preparasi Sampel Batuan untuk Uji PLI

Nilai PLI dapat dihitung dan digunakan untuk memprediksi nilai UCS masingmasing batuan. Batuan yang diuji adalah batu lempung dan batu pasir sebanyak 5 sampel masing- masingnya. Hasil Parameter dan hasil perhitungan nilai PLI tertera pada tabel 2 .

\section{Tabel 2.}

\section{Prediksi Nilai UCS dari Perhitungan Nilai PLI}

\begin{tabular}{|c|c|c|c|c|c|c|c|c|}
\hline $\begin{array}{c}\text { Kode } \\
\text { Sampel }\end{array}$ & $\begin{array}{c}\mathbf{d} \\
(\mathbf{c m})\end{array}$ & $\begin{array}{c}\mathbf{w 1} \\
\mathbf{( c m )}\end{array}$ & $\begin{array}{c}\mathbf{w 2} \\
\mathbf{( c m )}\end{array}$ & $\begin{array}{c}\text { D } \\
(\mathbf{c m})\end{array}$ & $\begin{array}{c}\text { P } \\
(\mathbf{k g})\end{array}$ & $\mathbf{F}$ & Is (MPa) & $\begin{array}{c}\text { UCS } \\
(\mathbf{M P a})\end{array}$ \\
\hline BP1 & 3.7 & 2.5 & 2.4 & 3.625 & 22 & 0.3099 & 0.0486 & 0.7441 \\
\hline BP2 & 3.6 & 2.5 & 2.55 & 3.78 & 34 & 0.3061 & 0.0785 & 1.2018 \\
\hline BP3 & 3.5 & 2.4 & 2.3 & 3.68 & 20 & 0.3022 & 0.0483 & 0.7395 \\
\hline BP4 & 3.65 & 2.6 & 2.6 & 3.565 & 10 & 0.308 & 0.0225 & 0.3445 \\
\hline BP5 & 3.6 & 2.8 & 2.9 & 3.71 & 10 & 0.3061 & 0.0785 & 1.2018 \\
\hline BL1 & 3.65 & 2.6 & 2.5 & 3.735 & 30 & 0.308 & 0.0677 & 1.0365 \\
\hline BL2 & 3.5 & 2.6 & 2.8 & 3.62 & 20 & 0.3022 & 0.0483 & 0.7395 \\
\hline BL3 & 3.6 & 2.3 & 2.35 & 3.795 & 22 & 0.3061 & 0.0508 & 0.7777 \\
\hline BL4 & 3.4 & 2.4 & 2.5 & 3.61 & 13 & 0.2983 & 0.0328 & 0.5022 \\
\hline BL5 & 3.6 & 2.55 & 2.6 & 3.66 & 18 & 0.3061 & 0.0416 & 0.6369 \\
\hline
\end{tabular}

Dari pengujian PLI untuk kedua sampel berupa batulanau dan batupasir diketahui bahwasannya nilai UCS rata-rata untuk batupasir sebesar $0.8463 \mathrm{MPa}$ dan nilai UCS rata-rata untuk batulanau sebesar 0.7386 Mpa. Persamaan empiris yang dihasilkan antara PLI dan UCS untuk batupasir yaitu $\mathrm{y}=15.31 \mathrm{x}$ dengan regresi $\left(\mathrm{R}^{2}=1\right)$ dan untuk batulanau, yaitu $\mathrm{y}=$ $15.31 \times$ dengan regresi $\left(R^{2}=1\right)$.

\section{Analisa Kestabilan Lereng BMK 35}

Analisa kestabilan lereng BMK 35 menggunakan grafik, yang diperkenalkan oleh Hoek dan Bray (1981). Perhitungan nilai FK dari lereng BMK 35 dapat dilihat pada Gambar 4.

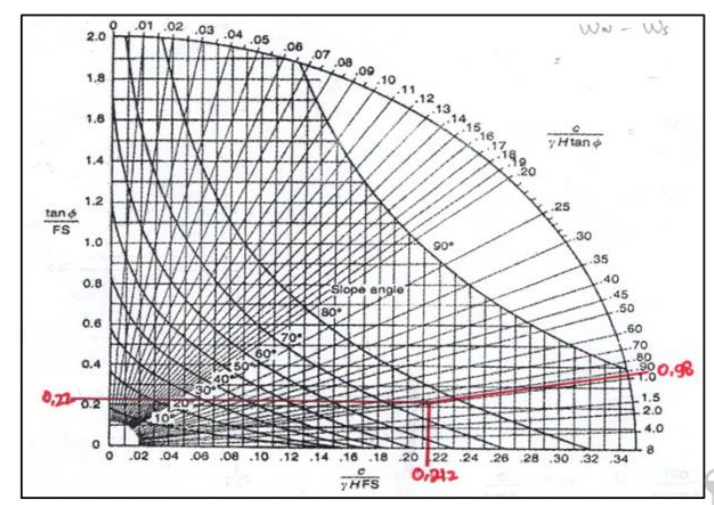

Tahapan perhitungan nilai FK:

a. Kondisi lereng benar-benar kering, maka grafik yang digunakana grafik nomor 1. $\gamma=20.055 \mathrm{KN} / \mathrm{m}^{3}, \mathrm{H}=22 \mathrm{~m}$, $\phi=30^{\circ}$ 


$$
\begin{array}{ll}
\text { Maka, } & \frac{c}{\gamma H \tan \phi}= \\
\frac{250 \mathrm{KN} / \mathrm{m}^{2}}{20.055 \mathrm{KN} / \mathrm{m}^{3} \times 22 \mathrm{~m} \times \tan (30)} & =0.98
\end{array}
$$

b. Perpotongan garis 0.98 dengan kurva sudut kemiringan lereng $\left(75^{\circ}\right)$ adalah 0.212, maka: $\frac{c}{\gamma H F S}=0.212$, maka $: \mathrm{FS}=$ $\frac{250 \mathrm{KN} / \mathrm{m}^{2}}{20.055 \mathrm{KN} / \mathrm{m}^{3} \times 22 \mathrm{~m} \times 0.212}=2.67$

c. Perpotongan garis 0.98 dengan $\frac{\tan \phi}{F S}$ adalah 0.22 ,

maka: $\frac{\tan \phi}{F S}=0.22$,

maka $: F S=\frac{\tan (30)}{0.22}=2.62$

Dari analisa kestabilan lereng menggunakan metode grafik Hoek dan Bray (1981) diketahui bahwasannya nilai FK untuk lereng BMK 35 kisaran 2.62 2.67 dan lereng dengan FK > 1 dinyatakan aman.

\section{KESIMPULAN}

1. Nilai UCS rata-rata dari pengujian BPI untuk batupasir diperoleh sebesar $0.8111 \mathrm{MPa}$ dan untuk batulanau diperoleh sebesar $1.2675 \mathrm{MPa}$, persamaan empiris yang dihasilkan antara BPI dan UCS untuk batupasir, yaitu $\mathrm{y}=5.099 \mathrm{x}$ dengan regresi $\left(\mathrm{R}^{2}=\right.$ 1) dan BPI terhadap UCS untuk batulanau, yaitu $\mathrm{y}=5.1 \mathrm{x}$ dengan regresi $\left(R^{2}=1\right)$.

2. Nilai UCS rata-rata dari pengujian PLI untuk batupasir sebesar $0.8463 \mathrm{MPa}$ dan untuk batulanau sebesar 0.7386 $\mathrm{MPa}$. Persamaan empiris yang dihasilkan antara PLI dan UCS untuk batupasir yaitu $\mathrm{y}=15.31 \mathrm{x}$ dengan regresi $\left(\mathrm{R}^{2}=1\right)$ dan untuk batulanau, yaitu $\mathrm{y}=15.31 \mathrm{x}$ dengan regresi $\left(\mathrm{R}^{2}=\right.$ 1).

3. Nilai Faktor Kemanan (FK) untuk lereng BMK 35 berada pada 2.62 2.67. Dengan nilai FK $>1$ maka kondisi lereng dinyatakan aman.

\section{DAFTAR PUSTAKA}

Astawa Rai, M, Kramadibrata, S, dan Kresna Wattimena, R. Mekanika Batuan. Bandung: ITB. 2014,

C.O. Aksoy. Determination of Instantaneous Breaking Rate by Geological Strength Index, Block Punch Index and Power of Impact Hammer for Various Rock Mass Condition. Turkey. Vol. 26, Pg: 534-540. 2011,

D.A. Mishra and A.Basu, Use of the Block Punch Test to Predict the Compressive and Tensile Strengths of Rocks, Indian Institute of Technology, India, Vol. $51 \mathrm{Pg}$ : 119-127. 2012,

Muntazir Abbas, S. Rock Mass Classification Systems. Freiberg : Bergakademie Freiberg, Geotechnical Institute. Pg: 148.2015,

Priagung Widodo,N. Penelitian K3 Penyanggaan Pada Penambangan Long Wall Semi Mekanis Batubara Bawah Tanah Dalam Rangka Mendukung Penyusunan Kebijakan K3 Tambang. Bandung: TEKMIRA.2010.

Resat Ulusay and Candan Gokceoglu, The Modified Block Punch Index Test, Applied Geology Division, Geological Engineering Department, Can. Geotech. J, Canada, Vol. 34. Pg: 991-1001. 1997.

Refky Adi Nata dan Alfi Sabri. Kestabilan Batuan Atap dan Dinding Tambang Batubara Bawah Tanah di PT. Allied indo coal jaya, Sawahlunto Sumatera Barat. Jurnal Sains dan Teknologi: Jurnal Keilmuan dan Aplikasi Teknologi Industri. Vol. 19 No. 2 Pg: 92-96. 2020, 
Refky Adi Nata and Murad M.S. Stand Up Time in Tunnel Base On Rock Mass Rating Bieniawski 1989. AIP Conference Proceeding. 1903 (1). 2017,

Syaeful Heri dan Kamajati Dathu. Analisis Karakteristik Massa Batuan Di Sektor Lemajung, Kalan, Kalimantan Barat. Jakarta: Jurnal Eksplorium Pusat Teknologi Bahan Galian Nuklit (Batan).Vol. 36 No. 1 Pg: 17-30.2015, 